\title{
Altered perception of the nutritional status of preschoolers by their parents: A risk factor for overweight and obesity
}

\author{
Karla L. Chávez Caraza, M.D. ${ }^{a}$, Julieta Rodríguez de Ita, M.D. ${ }^{a}$, Jesús Santos Guzmán, M.D. ${ }^{a}$, \\ Javán G. Segovia Aguirre, M.D. ${ }^{a}$, Diana C. Altamirano Montealvo, Student ${ }^{a}$ and \\ Víctor M. Matías Barrios, Student ${ }^{a}$
}

\begin{abstract}
Introduction. Many parentshave a misperception of their children's body size; in general, they underestimate overweight and obesity.

Objective. To identify the difference between parents' perception of their children's nutritional status and measured body mass index.

Population and methods. An analytical, descriptive and cross-sectional study was conducted among parents of children aged 2 to 6 years old. Children's body mass index was measured, and parents' perception was assessed using a visual scale of body size pictograms (drawings of body figures equivalent to body mass index percentiles).

Results. A total of 605 children and their parents were assessed. Seventy-four (12.2\%) were overweight and 87 were obese $(14.3 \%)$. There were 161 overweight or obese children, but $98.8 \%$ (159) of parents underestimated their children's nutritional status. Parents' underperception of their children's body size accounted for an $\mathrm{OR}=2.1 \pm 0.5, p=0.002(95 \%$ confidence interval [CI]: 1.32-3.32) for obesity and an $\mathrm{OR}=4.42 \pm 1.2$, $p<0.001$ (95\% CI: 2.631-7.439) for overweight. Conclusions. Among parents of overweight and obese children, 98.8\% (159) underestimated their children's weight status. Such underestimation by parents may be a significant risk factor for the development and/or persistence of overweight and obesity in their children.
\end{abstract}

a. Medicine School of Tecnológico de Monterrey, Monterrey

Campus. Pediatric Residency Program of the Multicenter System of Medical Residency Program, ITESM-SSNL,

Monterrey, Nuevo

León, Mexico.

E-mail address:

Jesús Santos

Guzmán, M.D.,

jsg@itesm.mx

Funding:

None.

Conflict of interest:

None.

Received: 08-17-2015

Accepted: 01-07-2016

\section{INTRODUCTION}

Childhood obesity is a global health problem. The worldwide overweight prevalence among preschoolers increased from $4.2 \%$ in 1990 to $6.7 \%$ in $2010 .{ }^{1}$ According to the National Survey on Nutrition and Health conducted in Mexico, overweight and obesity prevalence has increased among 5 year olds from $7.8 \%$ to $9.8 \%$ for obesity and from $18.8 \%$ to $23.8 \%$ for overweight. ${ }^{2}$ Childhood overweight and obesity may predispose to the development of diabetes or cardiovascular disease at an earlier age. ${ }^{3}$ Childhood overweight accounts for $25 \%$ of adult obesity, and becomes persistent at this age. ${ }^{4}$

Some studies explored parents' perception of their children's appearance and weight using standardized visual scales. ${ }^{5,6}$ However, a meta-analysis of parents' perception of childhood obesity indicates that parents are prone to have a misperception of their child's height to weight ratio, especially those who are overweight themselves.

Some studies suggest that parents fail to recognize their children's overweight because of their own weight, the child's younger age and gender, among other factors. ${ }^{8}$ In the low socioeconomic level group, many mothers see the fat child stereotype as healthier and happier versus the thin child, who is perceived as sickly. ${ }^{9}$ Jeffery et al. ${ }^{10}$ pointed out that obese parents tended to underestimate overweight and obesity in their children. Lampard et al. ${ }^{11}$ described that parents reported a higher concern about their children's body mass index (BMI) than their figure and worse quality of life.

\section{OBJECTIVE}

To identify the difference between parents' perception of their children's nutritional status and measured BMI.

\section{POPULATION AND METHODS}

An observational, analytical and cross-sectional study was conducted between June 2013 and July 2014 in children aged 2 to 6 years old and their parents. The perception of 
children's nutritional status was assessed using a seven body size pictogram. Children's weight, height and BMI were recorded. Children's BMI was compared to the nutritional status perceived by their parents using pictograms (drawing of body figures equivalent to BMI percentiles).

\section{Participants}

The study population included children aged between 2 and 6 years old and their parents. Participating children and parents attended either a children development center in San Nicolás de los Garza or either of two preschools in Santa Catarina, all located in the metropolitan area of Monterrey, Nuevo León, Mexico. The sample size was established based on childhood overweight and obesity prevalence in Mexico. The sample size was estimated using the formula to calculate a proportion in a finite population. It was 234 subjects for obesity and 480 subjects for overweight. In order to include both overweight and obesity cases, the sample was established at 480 subjects, with an additional 25\% (120 subjects) to account for incomplete data or dropouts. The final sample size was 600 subjects.

\section{Inclusion criteria}

Two to six year old children attending the study-selected childhood development centers whose parents had signed the informed consent form for participation.

\section{Exclusion criteria}

Subjects with other medical conditions having an effect on their weight (steroid use, hypothyroidism, chromosome abnormalities).

\section{Ethical aspects}

Parents signed an informed consent form and agreed to complete questionnaires and an assessment on their children so that the resulting information could be used in the study. Based on article 17 of the Mexican General Health Law in relation to Health Research, this study was classified as a no-risk investigation, so it was conducted once the institution granted its approval.

\section{Anthropometry}

Weight and height were measured, and BMI was calculated by dividing weight by the square of height. Height was measured in meters using a retractable tape measure, with the subject standing upright and looking straight ahead.
Weight was measured in kilograms using a Tanita BC 689 scale; measurements were done at any time of the day, with the subject standing and barefoot. Once BMI was estimated, BMI percentile was determined based on BMI curves established by the Centers for Disease Control and Prevention (CDC). ${ }^{12}$ BMI was classified as overweight or obesity based on the CDC's reference tables adjusted for sex and age. ${ }^{12}$ Overweight was defined as a BMI between $85 \%$ and $94 \%$, while obesity was defined as a $\mathrm{BMI} \geq 95 \%$.

\section{Seven body size pictograms}

To establish nutritional status as perceived by parents, a visual scale (pictogram) validated for 6 to 12 year-old children was used. The scale was made up of seven body sizes that accounted for physical appearance based on gender (boys and girls). ${ }^{13}$ Body figures corresponded to the $5^{\text {th }}, 10^{\text {th }}, 25^{\text {th }}, 50^{\text {th }}$, $75^{\text {th }}, 85^{\text {th }}$ and $95^{\text {th }}$ BMI percentiles according to the CDC's tables. Printed drawings of male and female body sizes were provided to parents. Fathers or mothers had to choose the drawing that, in their opinion, represented their children's body size. The chosen body size was compared to the measured BMI to establish if the perceived nutritional status was consistent with the corresponding BMI.

\section{Statistical analysis}

Descriptive statistics (average and standard deviation or percentage) were used to describe the study outcome measures. A logistic regression analysis was used to determine the difference between children's nutritional status as perceived by parents using pictograms and the children's height to weight ratio. An 0.05 or lower alpha error was considered significant. Sensitivity and specificity were analyzed using prevalence values reported in Mexico: $9.8 \%$ for obesity and $23.8 \%$ for overweight in children younger than 5 years old. Sensitivity was defined as the correct perception of overweight and obesity (true positives / overweight/obesity). Specificity was defined as the correct perception of normal weight (true negatives/normal weight). Statistical analysis was done using the STATA 10 software (StataCorp, College Station, TX, USA).

\section{RESULTS}

A total of 605 children aged between 2 and 6 years old ( 314 boys, $51.9 \%$ ) were assessed. Their average age was $4.2 \pm 1.2$ years old. Among the total population, overweight and obesity prevalence was $12.2 \%$ and $14.3 \%$, respectively. 
Among boys, $243(77.4 \%)$ had a low or normal weight, $26(8.3 \%)$ were overweight and $45(14.3 \%)$, obese. Among girls, 201 (69\%) had a low or normal weight, $48(16.5 \%)$ were overweight and $42(14.5 \%)$, obese. Parents' perception of body mass index was lower than that measured for $32.5 \%$ of boys and for $36.8 \%$ of girls (Table 1 ).

A distorted perception of pictograms, i.e. parents' perceiving that their children's nutritional status was thinner than their actual normal BMI ( $>85^{\text {th }}$ percentile), corresponded to $18.5 \%$ of boys and $10.9 \%$ of girls. Among overweight children $\left(B M I \geq 85^{\text {th }}\right.$ and $<95^{\text {th }}$ percentile), it corresponded to $100 \%$ of boys and girls; and among obese children (BMI $\geq 95^{\text {th }}$ percentile), it corresponded to $95.6 \%$ of boys and $100 \%$ of girls (Table 1).
Out of 605 children, $161(26 \%)$ were overweight or obese. Of these, $2(1.2 \%)$ were adequately perceived by their parents, while the parents of $159(97.7 \%)$ had a misperception of their children's body image. Table 1 shows parents' perception of their children's BMI based on the body size pictograms for overweight and obese children groups.

Regarding the obesity outcome measure, the fact that parents underestimated body size compared to measured BMI accounted for an odds ratio (OR) of 2.1, standard error $(\mathrm{SE})=0.49$, $p=0.002$ (95\% confidence interval [CI]: 1.32-3.32). However, perceiving a body size that was thinner than the measured BMI was associated with a risk for overweight: $\mathrm{OR}=4.42, \mathrm{SE}=1.17, p<0.001$ (95\% CI: 2.631-7.439). OR values by gender for overweight and obesity are shown in Table 2.

TABLE 1. Parents' perception of their children's body size using pictograms

Parents' perception using pictograms (drawings of body figures equivalent to percentiles). Adapted from Collins M. E. (1991). Body figure perceptions and preferences among preadolescent children. International Journal of Eating Disorders 1991;10(2):199-208.
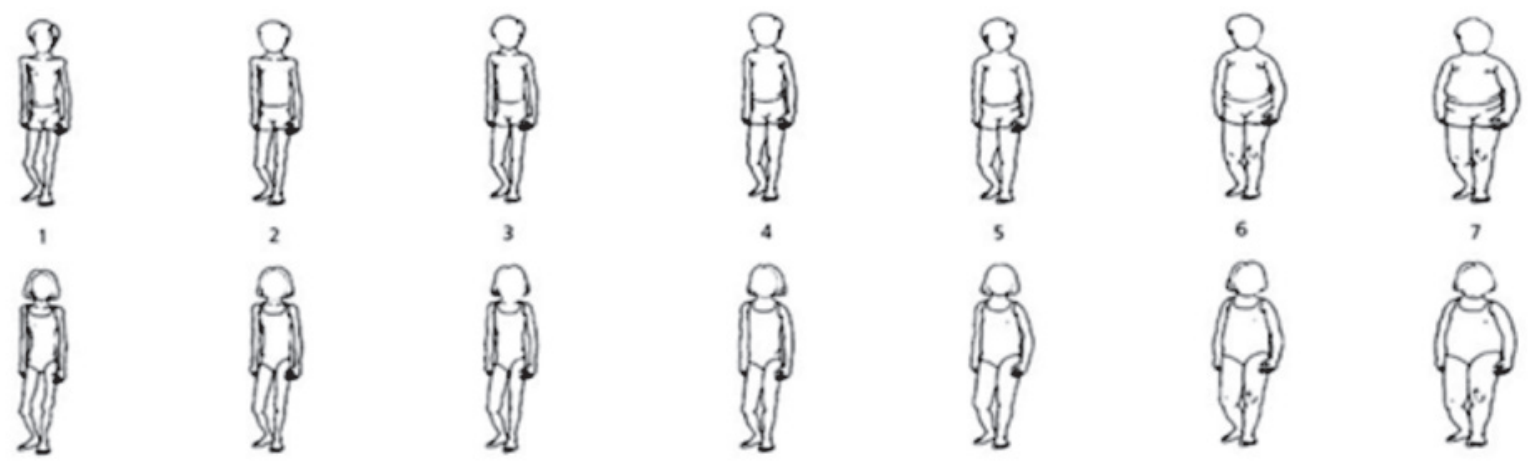

BMI (percentiles) $\begin{array}{r}\text { Total no } \\ \text { of cases }\end{array}$

P 5

$\mathrm{P} 10$

P 25

$\mathrm{P} 50$

P 75

P 85

P 95

\begin{tabular}{ll|l|l|l|l|l|l|l|} 
P 5 & 91 & 1 & 7 & 48 & 32 & 3 & 0 & 0 \\
P 10 & 58 & 1 & 4 & 28 & 22 & 3 & 0 & 0 \\
P 25 & 116 & 0 & 2 & 41 & 70 & 3 & 0 & 0 \\
\cline { 2 - 9 } P 50 & 151 & 0 & 5 & 35 & 103 & 8 & 0 & 0 \\
P 75 & 28 & 0 & 0 & 7 & 17 & 4 & 0 & 0 \\
P 85 & 43 & 0 & 1 & 4 & 29 & 9 & 0 & 0 \\
P 90 & 31 & 0 & 0 & 0 & 21 & 10 & 0 & 0 \\
P95 & 43 & 0 & 0 & 3 & 12 & 19 & 7 & 2 \\
> P 95 & 44 & 0 & 0 & 1 & 15 & 23 & 5 & 0 \\
Total & 605
\end{tabular}

* The white area indicates that parents underestimated their children's body size in comparison to their BMI. The black area indicates that parents perceived that their children's body size was consistent with their BMI. The gray area indicates that parents perceived that their children's body size was larger in comparison to their BMI. For overweight, sensitivity was $67.6 \%$ and specificity was $68.0 \%$. For obesity, sensitivity was $51.7 \%$ and specificity was $66.2 \%$.

BMI: body mass index. 
Sensitivity of parents' perception to detect obesity was $51.7 \%$ (95\% CI: 40.8-62.6), while specificity was $66.2 \%$ (95\% CI: $62-70.3)$, with a positive predictive value (PPV) of $14.3 \%$ and a negative predictive value (NPV) of $92.7 \%$. In the case of obesity, sensitivity was $67.6 \%$ (95\% CI: 55.7-78), while specificity was $68 \%$ (95\% CI: 63.8 71.9), with a PPV of $18.7 \%$ and a NPV of $95.1 \%$.

\section{DISCUSSION}

Obesity prevalence in our population was $14.3 \%$, higher than that reported in the literature. ${ }^{2}$ In the group of overweight or obese children, only $2(1.2 \%)$ were correctly perceived as overweight and obese by their parents, while 159 (98.8\%) were perceived by their parents as having a normal weight, therefore underestimating their height to weight ratio.

A possible cause of parents' misperception regarding their children's height to weight ratio may be the global increase in obesity prevalence, which makes a larger body size to be perceived as normal by the general population, in concordance with Maximova et al.'s reports. ${ }^{14}$

Results obtained are consistent with those described by other investigations, which report that over $50 \%$ of parents whose children are overweight or obese perceive their nutritional status as lower than that measured. In Australia, $88 \%$ and $90 \%$ of mothers of overweight and obese children, respectively, underestimated their children's weight status. ${ }^{15}$ While in Canada, a study comparing parents' and doctors' perception in relation to their children's weight described that $47 \%$ of parents underestimated their children's weight status. ${ }^{16}$ In Mexico, it has been reported that more than $79 \%$ of parents of overweight or obese children underestimated their children's weight status; ${ }^{9}$ in addition, 83\% of mothers of overweight or obese children underestimated their children's weight. ${ }^{17-19}$
It is worth noting that for $224(50 \%)$ boys and girls with a $\mathrm{BMI}<85^{\text {th }}$ percentile, the pictogram was overestimated in comparison to their measured BMI, while this did not occur for any of the overweight or obese children.

Our study results are relevant in our setting because most studies on this topic have been conducted in developed countries.

Cultural and economic differences may affect parents' perception, so it is difficult to make a direct comparison to those results.

For example, in the study by Hudson, among normal weight children, $6.3 \%$ of boys and $2.5 \%$ of girls were incorrectly perceived by their parents, but among overweight and obese children, $83.3 \%$ of boys and $79.9 \%$ of girls were incorrectly categorized by their parents as having a normal weight according to their height and age. ${ }^{8}$ Souto et al. ${ }^{9}$ reported that up to $43 \%$ of mothers of $6-24$ month old infants with a low socioeconomic level underestimated their children's weight status.

Data described in a systematic review on the differences between parents' perception and children's measured weight were country, place, number of children included, male to female ratio, which parent provided the information, and tables used to categorize BMI. ${ }^{20}$

This study included all these data, but did not differentiate whether fathers or mothers had provided the information. Parents' perception of their children's height to weight ratio was assessed using a visual tool for each gender because other studies using visual scales showed that a higher percentage of overweight and obese children were correctly perceived by their parents compared to those using verbal questionnaires. ${ }^{20}$ However, the visual scale used in this study has only been validated for 6 to 12 year olds, not for younger children. ${ }^{13}$

There are other risk factors leading to parents' underestimating their children's weight to height

TABLE 2. Risk estimation resulting from parents' underperception of measured overweight and obesity

\begin{tabular}{lccc}
\hline & $\begin{array}{c}\text { Male gender } \\
(\mathbf{n}=\mathbf{3 1 4})\end{array}$ & $\begin{array}{c}\text { Female gender } \\
(\mathbf{n = 2 9 1})\end{array}$ & $\begin{array}{c}\text { Total } \\
(\mathbf{n}=\mathbf{6 0 5})\end{array}$ \\
\hline Perception of obesity & OR 1.65 $\pm .56(\mathrm{SE})$, & OR 2.63 $\pm 0.86(\mathrm{SE})$, & OR 2.1 $\pm 0.49(\mathrm{SE})$, \\
lower than that measured & $p=0.137(95 \%$ CI: 0.852-3.204) & $p=0.003(95 \%$ CI: $1.38-5.001)$ & $p=0.002(95 \%$ CI: $1.32-3.32)$ \\
Perception of overweight & OR $8.27 \pm 4.23(\mathrm{SE})$, & OR 3.55 $\pm 1.16(\mathrm{SE})$, & OR 4.42 $\pm 1.17(\mathrm{SE})$, \\
lower than that measured & $p<0.001(95 \%$ CI: 3.025-22.603) & $p<0.001(95 \%$ CI: $1.873-6.742)$ & $p<0.001(95 \%$ CI: 2.631-7.439) \\
\hline
\end{tabular}

OR: odds ratio; SE: standard error; CI: confidence interval. 
ratio in comparison to the measured ratio. The study conducted by Intagliata et al. ${ }^{21}$ reported that, in a population of preadolescents, there was an association between parental education level and a more accurate perception of their children's measured BMI. Parents who had completed university education had a better perception of their children's height to weight ratio $(\mathrm{OR}=0.11)$.

Another study demonstrated that mothers with a lower education level incorrectly categorized body sizes and underestimated health problems associated to each figure, and that the estimation of their children's weight was influenced by the children's and mothers' own weight. ${ }^{8}$

A limitation of this study is that it did not specify whether mothers or fathers should complete the questionnaire, so it was not possible to establish differences in perception by parents' gender. In addition, this study sets a precedent regarding parents' perception of their overweight or obese preschool children in Mexico, given that, to date, it had not been described in this population.

Altered perceptions of parents of their children's height to weight ratio become a barrier for the prevention and management of childhood obesity. For this reason, we estimated the sensitivity and specificity of parents to detect overweight and obesity. Sensitivity to detect obesity was only $51.7 \%$, with a low specificity of $66.2 \%$; while sensitivity and specificity to detect overweight were somewhat higher: $67.6 \%$ and $68 \%$, respectively. For this reason, we believe that doctors should help parents to recognize their children's overweight by interpreting BMI and discussing children's weight status.

Consistent with what has been reported in other studies, ${ }^{14}$ interventions to prevent childhood obesity should aim at raising parents' concern by having a more adequate perception of their children's body size and increase knowledge on the long-term effects of overweight on their children's health.

The cause of this phenomenon should be further investigated to achieve effective interventions. An actual identification of overweight children by their parents is the first step to manage obesity.

\section{CONCLUSION}

Among parents of overweight or obese children, 98.8\% underestimated their children's nutritional status when using pictograms. A misperception of a child's measured height to weight ratio by parents may be a significant risk factor for the development and/or maintenance of overweight and obesity.

\section{Acknowledgments}

We would like to thank the Child Development Center CENDI 12 "Jean Piaget" for providing the facilities to conduct the study.

\section{REFERENCES}

1. De Onis M, Blössner M, Borghi E. Global prevalence and trends of overweight and obesity among preschool children. Am J Clin Nutr 2010;92(5):1257-64.

2. Gutierrez JP, Rivera-Dommarco J, Shamah-Levy T, Villalpando-Hernández S, et al. Encuesta Nacional de Salud y Nutrición 2012. Resultados nacionales. Cuernavaca: Instituto Nacional de Salud Pública; 2012.

3. Freedman DS, Khan LK, Dietz WH, Srinivasan SR, et al. Relationship of childhood obesity to coronary heart disease risk factors in adulthood: the Bogalusa HeartStudy. Pediatrics 2001;108(3):712-8.

4. Freedman DS, KatzmarzykPT, Dietz WH, SrinivasanSR, et al. Relation of body mass index and skinfold thicknesses to cardiovascular disease risk factors in children: the Bogalusa Heart Study. Am J Clin Nutr 2009;90(1):210-6.

5. Wake M, Salmon L, Waters E, Wright M, et al. Parentreported health status of overweight and obese Australian primary school children: a cross-sectional population survey. Int J Obes Relat Metab Disord 2002;26(5):717-24.

6. Eckstein KC, Mikhail LM, Ariza AJ, Thomson JS, et al. Parents' perceptions of their child's weight and health. Pediatrics 2006;117(3):681-90.

7. Doolen J, Alpert PT, Miller SK. Parental disconnect between perceived and actual weight status of children: a metasynthesis of the current research. J Am Acad Nurse Pract 2009;21(3):160-6.

8. Hudson E, McGloin A,McConnon A. Parental weight (mis) perceptions: factors influencing parents' ability to correctly categorise their child's weight status. Matern Child Health J 2012;16(9):1801-9.

9. Souto-Gallardo MC, Jiménez-Cruz A, Bacardí-Gascón M. Parents perception of weight status of Mexican preschool children using different tools. Arch Latinoam Nutr 2011;61(4):382-8.

10. Jeffery AN, Voss LD, Metcalf BS, Alba S, et al. Parents' awareness of overweight in themselves and their children: cross sectional study within a cohort (EarlyBird 21). BMJ 2005;330(7481):23-4.

11. Lampard AM, Byrne SM, Zubrick SR, Davis EA. Parents' concern about their children's weight. Int J Pediatr Obes 2008;3(2):84-92.

12. Fryar CD, Gu Q, Ogden CL. Anthropometric reference data for children and adults: United States, 2007-2010. Vital Health Stat 11 2012;(252):1-48.

13. Truby H, Paxton SJ. Development of the Children's Body Image Scale. Brit J Clin Psychol 2002;41(Pt 2):185-203.

14. Maximova K, McGrath JJ, Barnett T, O'Loughlin J, et al. Do you see what I see? Weight status misperception and exposure to obesity among children and adolescents. Int J Obes (Lond) 2008;32(6):1008-15.

15. Mitchell R, WakeM,Canterford L, Williams J. Does maternal concern about children's weight affect children's body size perception at the age of 6.5? A community-based study. Int J Obes (Lond) 2008;32(6):1001-7. 
16. Chaimovitz R, Issenman R, Moffat T, Persad R. Body perception: do parents, their children, and their children's physicians perceive body image differently? J Pediatr Gastroenterol Nutr 2008;47(1):76-80.

17. Jimenez-Cruz A, Bacardi-Gascon M, Castillo-Ruiz O, Mandujano-Trujillo Z, et al. Low income, Mexican mothers' perception of their infants' weight status and beliefs about their foods and physical activity. Child Psychiatry Hum Dev 2010;41(5):490-500.

18. Killion L, Hughes SO, Wendt JC, Pease D, et al. Minority mothers' perceptions of children's body size. Int J Pediatr Obes 2006;1(2):96-102.
19. Genovesi S, Giussani M, Faini A, Vigorita F, et al. Maternal perception of excess weight in children: a survey conducted by pediatricians in the province of Milan. Acta Paediatr 2005;94(6):747-52.

20. Rietmeijer-Mentink M, Paulis WD, van Middelkoop M, Bindels PJ, et al. Difference between parental perception and actual weight status of children: a systematic review. Matern Child Nutr 2013;9(1):3-22.

21. Intagliata V, Ip EH, Gesell SB, Barkin SL. Accuracy of self- and parental perception of overweight among Latino preadolescents. N C Med J 2008;69(2):88-91. 